Disclosure of Interests: Maha Jamal Abdelkadir: None declared, Amber Korver: None declared, Martijn Kuijper: None declared, Deirisa Lopes Barreto: None declared, Cathelijne Appels: None declared, Anneke Spoorenberg Grant/research support from: Received unrestricted grants from Pfizer, Novartis and Abbvie pharmaceuticals. They had no influence in design and conduct of the study., Consultant for: Abbvie, Pfizer, MSD, UCB, and Novartis, Bart Koes: None declared, Johanna Hazes: None declared, Lonneke van Hoeven: None declared, Angelique Weel: None declared

DOI: 10.1136/annrheumdis-2019-eular.2027

\section{THU0363 DO ILLNESS PERCEPTIONS AND COPING CHANGE OVER TIME IN PATIENTS RECENTLY DIAGNOSED WITH AXIAL SPONDYLOARTHRITIS? A 2-YEAR FOLLOW-UP STUDY IN THE SPACE COHORT}

Miranda van Lunteren ${ }^{1}$, Robert B.M. Landewé ${ }^{2,3}$, Camilla Fongen ${ }^{4}$, Roberta Ramonda ${ }^{5}$, Désirée van der Heijde ${ }^{1}$, Floris A. van Gaalen ${ }^{1}$. ${ }^{1}$ LUMC, Leiden, Netherlands; ${ }^{2}$ ARC, Amsterdam, Netherlands; ${ }^{3}$ Zuyderland Hospital, Heerlen, Netherlands; ${ }^{4}$ Diakonhjemmet Hospital, Oslo, Norway; ${ }^{5}$ University of Padova, Padova, Italy

Background: In recently diagnosed axial spondyloarthritis (axSpA), illness perceptions are important in the relationship between back pain and Health-Related Quality of Life (HRQoL) or work productivity loss (WPL). ${ }^{1}$ Coping did not have an additional impact on this relationship, but was associated with HRQoL. Therefore, health outcomes might be improved by influencing illness perceptions and possibly coping. With respect to disease management, it is important to know if illness perceptions and coping remain stable over time. However hardly any information is available, especially for early axSpA, as the few studies that have been conducted mostly had a cross-sectional design and investigated patients with longstanding radiographic axSpA.

Objectives: To investigate if illness perceptions and coping strategies change in the first 2 years after diagnosis of axSpA.

Methods: Patients diagnosed with axSpA and $\geq 1$ follow-up visit (1 year and/or 2 years) in the SPACE cohort were included in the analysis. Mixed linear models were used to test if illness perceptions (measured by the Revised Illness Perception Questionnaire (IPQ-R, scale 1-5)), coping (Coping with Rheumatic Stressors (CORS, scale 1-4)), back pain (scale 0-10), HRQoL (physical (PCS) and mental component summary (MCS), scale $0-100$, of the 36-item Short-Form Health Survey (SF-36)), WPL and activity impairment (Work Productivity and Activity Impairment (WPAl, range $0-100 \%)$ ) changed over time. Results were stratified for gender and age when the interaction term was statistically significant $(\mathrm{p}<0.05)$.

Results: In total, 150 axSpA patients (mean age 30.4 years, 51\% female, $65 \%$ HLA-B27+) were analysed. Baseline mean back pain (SD) was 4.0 (2.5), PCS was 28.8 (14.0), MCS was 47.8 (12.4), WPL was $34.1 \%$ (29.8) and activity impairment was $38.7 \%$ (27.9). Illness perceptions and coping strategies showed minimal changes over time (Table 1, 2). Over two years patients remained having negative illness perceptions (which were important in the association between back pain and health outcomes in the previous study). For example, over 2 years patients had strong beliefs in severe consequences ('consequences'), had still negative emotions towards their disease ('emotional representation') and had strong beliefs in chance ('chance') as a cause for axSpA.

Over two years, back pain (mean change \pm SD is $-1.5 \pm 2.2$ ) and activity impairment $(-14.4 \% \pm 27.2)$ decreased, PCS (11.1 \pm 13.3$)$ and WPL $(-15.3 \% \pm 28.7)$ improved statistically significantly, but MCS did not change $(0.7 \pm 13.9)$.

Abstract THU0363-Table 1.

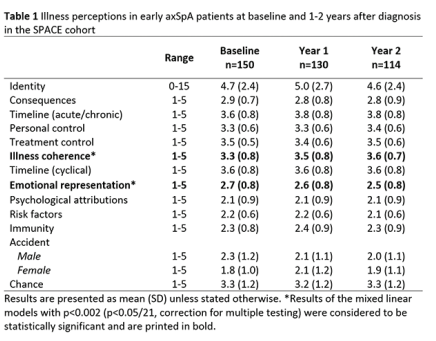

Abstract THU0363 -Table 2.

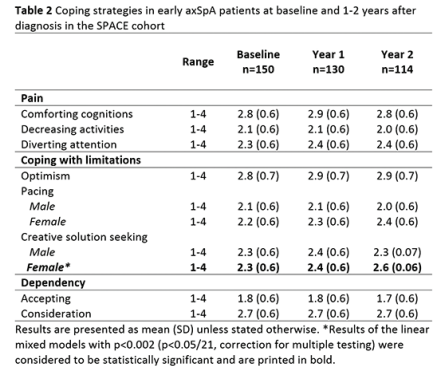

Conclusion: Despite clear improvements in back pain and health outcomes over 2 years, illness perceptions experienced and coping strategies applied by the patients showed little change in recently diagnosed axSpA patients. Further research is recommended why despite improved outcomes illness perceptions do not change, to investigate the impact of these unchanged illness perceptions and coping strategies on health outcomes and how these negative perceptions can be improved.

\section{REFERENCES:}

[1] van Lunteren, et al. AC\&R 2018.

Disclosure of Interests: Miranda van Lunteren: None declared, Robert B M. Landewé: None declared, Camilla Fongen: None declared, Roberta Ramonda: None declared, Désirée van der Heijde Consultant for: AbbVie Amgen, Astellas, AstraZeneca, Bristol-Myers Squibb, Boehringer Ingelheim, Celgene, Daiichi, Eli-Lilly, Galapagos, Gilead, GlaxoSmithKline, Janssen, Merck, Novartis, Pfizer, Regeneron, Roche, Sanofi, Takeda, Union Chimique Belge, Floris A. van Gaalen: None declared

DOI: 10.1136/annrheumdis-2019-eular.558

\section{THU0364 THE DIAGNOSTIC UTILITY OF THE RELATION BETWEEN MRI BONE MARROW EDEMA AND OTHER TYPES OF MRI LESIONS IN THE SACROILIAC JOINTS IN AXIAL SPONDYLOARTHRITIS}

Sengül Seven ${ }^{1}$, Pernille Hededal ${ }^{2}$, Mikkel Ǿstergaard ${ }^{1}$, Lone Morsel-Carlsen ${ }^{2}$, Inge Juul Sørensen ${ }^{1}$, Birthe Bonde ${ }^{3}$, Gorm Thamsborg ${ }^{1}$, Jens Jørgen Lykkegaard ${ }^{1}$, Oliver Hendricks ${ }^{4}$, Niklas Rye Jørgensen ${ }^{5}$, Susanne Juhl Pedersen ${ }^{1}$.

${ }^{1}$ Rigshospitalet - Glostrup, Copenhagen Center for Arthritis Research Center for Rheumatology and Spine Diseases, Glostrup, Denmark; ${ }^{2}$ RigshospitaletGlostrup, Department of Radiology, Glostrup, Denmark; ${ }^{3}$ Birthe Bonde klinikken, København, Denmark; ${ }^{4}$ King Christian X's Rheumatism Hospital, Gråsten, Denmark; ${ }^{5}$ Rigshospitalet - Glostrup, Department of Clinical Biochemistry, Glostrup, Denmark

Background: MRI detected bone marrow edema (BME) plays a centra role in the ASAS (Assessment of Spondyloarthritis International Society) classification criteria for axial spondyloarthritis $(\operatorname{axSpA})[1,2]$. However $\mathrm{BME}$ in the sacroiliac joints (SIJs) is also present in other conditions[3-7]. Objectives: The aim was to investigate the diagnostic utility of MRI BME and its relation to different types of MRI SIJ lesions to separate patients with axSpA from persons with other conditions.

Methods: The MASH study is a prospective cross-sectional study of 204 participants, aged $\leq 45$ yrs. The study included patients with axSpA $(n=41)$ women with $(n=46)$ and without $(n=14)$ postpartum pain, patients with lumbar disc herniation $(n=25)$, persons with hard physical labor (cleaning assistants) $(n=25)$, long-distance runners $(>30 \mathrm{~km} /$ week) $(n=23)$ and healthy men $(n=29)$. Participants with pain should all have VAS pain $>2$ (on a scale $0-10$ ) for $\geq 2$ months. Participants in the non-axSpA groups were not allowed to have any clinical SpA features or rheumatological conditions. Participants underwent clinical, laboratory and MRI examination (semi-coronal STIR and T1W sequences) of the SIJs. MRIs were evaluated for BME, erosion, fat, ankylosis, and sclerosis according to the SPARCC MRI definitions of lesions[8, 9] by two independent readers. In nine slices of the cartilaginous compartment each SIJ was separately assessed for the presence of BME in relation to joint space and each of the above-mentioned structural lesions (range of total score per patient: 0-18).

Results: The table shows the clinical characteristics of each group, the mean MRI scores and MRI cut-off levels for the concordant reads. BME located adjacent to joint space, adjacent to erosions and adjacent to fat were more frequent in patients with $\operatorname{axSpA}$, but these lesions were also seen in the other study groups, mainly women with postpartum pain When increasing amounts of lesions were required (higher cut-offs) 